ПРИ проводились в феврале 2018 года.

\section{Библиографические ссылки}

1. Сатокин В.В., Мусиенко П.Б., Виртуальные испытания корпуса сопла РДТТ. Космическая техника. Ракетное вооружение. Днепр, ГП «КБ «Южное». 2015. № 3. С. 46-49.
2 Сатокин В.В. Разработка и апробация программного модуля для построения виртуальных моделей реальных конструкций в комплексе ANSYS. Космическая техника. Ракетное вооружение. Днепропетровск, ГП «КБ «Южное». 2016. № 2. С. 57-59.

\title{
УДК 629.78.064.5 \\ ОПРЕДЕЛЕНИЕ ХАРАКТЕРИСТИК ХИМИЧЕСКИХ ИСТОЧНИКОВ ТОКА С ЦЕЛЬЮ ПОДТВЕРЖДЕНИЯ ВОЗМОЖНОСТИ ИХ ИСПОЛЬЗОВАНИЯ В СОСТАВЕ СИСТЕМ ЭЛЕКТРОСНАБЖЕНИЯ
}

\author{
В.А. Пырец, В.С. Рева, К.Н. Земляной, О.В. Гаврилов, К.В. Безручко \\ Государственное предприятие «Конструкторское бюро «Южное» имени акад. \\ М.К. Янгеля, ул. Криворожская, 3, г. Днепр, 49008, Украина, e-mail: info@yиzhnoye.com
}

Розглянуто питання визначення гарантованого залишкового терміну служби акумуляторної батареї, який дозволяс точно визначити параметри і характеристики, а також спрогнозувати їх у процесі іiі життсвого циклу. Розглянуто один із способів підтвердження працездатності хімічних джерел струму і визначення їх подальшої безвідмовної роботи, якими є прискорені кліматичні випробування. Також приведено залежність розрядної смності хімічних джерел струму у вигляді математичних моделей, що дозволяє при відомій по результатах вимірювань смності при прискорених кліматичних випробуваннях визначити характеристики хімічних джерел струму при нормальних умовах і навпаки.

Ключові слова: хімічне джерело струму, смність, експериментальна база, математична модель.

In the article the question definitions of the guaranteed residual service life of the storage battery, which allows you to accurately determine the parameters and characteristics, and also to predict them in the course of its life cycle. One of the methods of confirming the operability of chemical current sources and determining their further failure-free operation is considered, which are accelerated climatic tests. Also shown is the discharge capacity of chemical sources of current in the form of mathematical models, what makes it possible to determine the characteristics of chemical sources of current under normal conditions, and vice versa, when the capacitance is known from measurements of accelerated climatic tests.

Keywords: chemical current source, capacity, experimental base, mathematical model.

Рассмотрен вопрос определения гарантированного остаточного срока службы аккумуляторной батареи, который позволяет точно определить параметры и характеристики, а также спрогнозировать их в процессе ее жизненного цикла. Рассмотрен один из способов подтверждения работоспособности химических источников тока и определения их дальнейшей безотказной работы, которыми являются ускоренные климатические испытания. Также приведена зависимость разрядной емкости химических источников тока в виде математических моделей, что позволяет при известной по результатам измерений емкости при ускоренных климатических испытаниях определить характеристики химических источников тока при нормальных условиях и наоборот.

Ключевые слова: химический источник тока, емкость, экспериментальная база, математическая модель.

Введение. Одной из важнейших задач систем электроснабжения (СЭС) как стационарных, так и подвижных стартовых комплексов является обеспечение бесперебойности электропитания технологического оборудования, участвующего в подготовке и пуске ракеты космического назначения (РКН). Для этих задач в СЭС ппименяются источники беспепебойного (C) Пырец В.А., Рева В.С., Земляной К.Н., Гаврилов О. питания (ИБП), накопителем электрической энергии в которых являются химические источники тока (ХИТ). При эксплуатации ИБП основными параметрами, характеризующими состояние ХИТ, являются емкость, заряженность, напряжение разомкнутой цепи, внутреннее сопротивление, вольт-амперные и заряднопазпялные хапактеристики. Реальное 
состояние ХИТ проверяют путем измерения фактической емкости батареи разрядом на нагрузку (разряд-зарядразряд) с использованием специального испытательного оборудования. Однако в реальных условиях это существенно усложняет процесс эксплуатации и технического обслуживания данных систем [1-3]. На ранее разработанных подобных комплексах, как правило, ХИТ снимали с эксплуатации по окончании гарантийного срока или срока эксплуатации, что нецелесообразно по техническим и экономическим составляющим [4]. Комплексный подход определения гарантированного остаточного срока службы ХИТ позволяет точно определить параметры и характеристики ХИТ, а также спрогнозировать их в процессе еe жизненного цикла.

Постановка задачи. Целью исследования является определение текущих характеристик ХИТ от температуры. Методика эксперимента заключается в следующем. Циклирование ХИТ производится при их нагреве до температуры $60^{\circ} \mathrm{C}$ и поддержании заданной температуры по поверхности ХИТ и окружающей среды в течение длительного времени с высокой точностью.

Затем проводятся четыре трениировочных цикла на каждом ХИТ при нормальных условиях $\left(20^{\circ} \mathrm{C}\right)$ и определяется емкость, до момента потери ими $20 \%$ номинальной емкости. В дальнейшем проводятся еще десять циклов в интервале $25-60{ }^{\circ} \mathrm{C}$ с шагом $5{ }^{\circ} \mathrm{C}$ и точностью $0,1^{\circ} \mathrm{C}$. Циклирования ХИТ для определения влияния на их параметры температуры проводятся согласно разработанной последовательности проведения циклирования ХИТ при различной температуре, а результаты эксперимента будут использованы для доработки математических моделей.

Основная

часть.

ХИТ

характеризуется следующими основными параметрами и характеристиками, которые влияют на их работоспособность (рис. 1, красным цветом отмечены критические характеристики, синим - некритические) [3]:

- типом электрохимической системы (литий-ионные, свинцово-кислотные, никель-кадмиевые и т.д.);

- напряжением (разность потенциалов, погруженных в электролит и действующих на положительном и отрицательном электродах);

- электрической емкостью (способность аккумулятора накапливать и отдавать электрическую энергию);

- внутренним сопротивлением;

- током саморазряда (процесс разряда аккумулятора, в котором отсутствует какая-либо нагрузка);

- сроком службы (число циклов заряд-разряд и значительно зависит от условий эксплуатации аккумулятора);

- температурой.

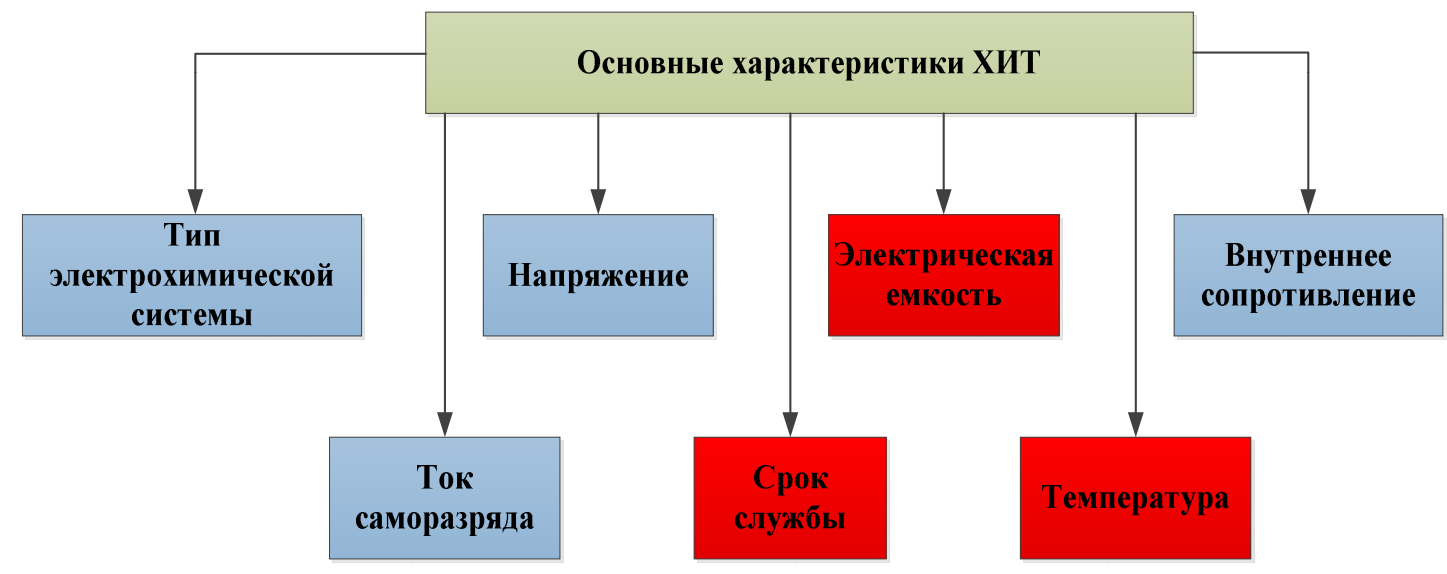

Рис. 1. Основные характеристики ХИТ 
ХИТ, как правило, могут эксплуатироваться в различных режимах эксплуатации, основными из которых являются:

- буферный режим (режим постоянного подзаряда, режим, при котором ХИТ всегда подключен к источнику постоянного тока);

- циклический режим (режим работы, предполагающий многократное проведение заряда и разряда ХИТ; при этом режиме эксплуатации производится заряд ХИТ и отключение его от зарядного устройства);

- дежурный режим (режим работы ХИТ, при котором он в процессе эксплуатации находится в режиме ожидания в заряженном состоянии);
- стартерный режим (режим работы ХИТ, при котором ХИТ предназначен для запуска основного генератора тока; после запуска основного генератора вся система питается от него, а ХИТ переключается на заряд);

- режим основного источника (режим работы, при котором заряженный ХИТ разряжается на потребителя энергии без дальнейшего заряда);

- режим хранения (режим работы, при котором ХИТ находится в нерабочем состоянии до ввода в эксплуатацию, либо после консервации) [4-6].

В табл. 1 представлены режимы работы ХИТ и их характеристики.

Основные режимы эксплуатации ХИТ

Таблица 1

\begin{tabular}{|c|c|}
\hline Основные режимы эксплуатации ХИТ & Характеристики, присущие режиму \\
\hline Буферный режим & $\begin{array}{l}\text { I3 - ток заряда } \\
\text { Ip - ток разряда } \\
\text { Q - емкость } \\
\text { U - напряжение }\end{array}$ \\
\hline Циклический режим & $\begin{array}{l}\text { Iз - ток заряда } \\
\text { Ip - ток разряда } \\
\text { Qp - разрядная емкость } \\
\text { Q3 - зарядная емкость } \\
\end{array}$ \\
\hline Дежурный режим & $\begin{array}{l}\text { Iподз - ток подзаряда } \\
\mathrm{U}_{\text {нРц }} \text { - напряжение разомкнутой цепи } \\
\mathrm{Q} \text { - емкость } \\
\mathrm{C} \text { - заряженность }\end{array}$ \\
\hline Стартерный режим & $\begin{array}{l}\text { U } \mathrm{U}_{\mathrm{P}} \text { - напряжение разряда; } \\
\mathrm{Ip} \text { - ток разряда } \\
\text { Qp - разрядная емкость } \\
\text { Вольт-амперная характеристика }\end{array}$ \\
\hline Режим основного источника & $\begin{array}{l}\mathrm{Ip} \text { - ток разряда } \\
\mathrm{Qp} \text { - разрядная емкость } \\
\mathrm{U}_{\mathrm{P}} \text { - напряжение разряда; }\end{array}$ \\
\hline Режим хранения & $\begin{array}{l}\mathrm{U}_{\text {НРц }} \text { - напряжение разомкнутой цепи } \\
\mathrm{Qp} \text { - разрядная емкость } \\
\mathrm{C} \text { - заряженность }\end{array}$ \\
\hline
\end{tabular}

Методы определения состояния ХИТ показаны на рис. 2.

Метод определения состояния аккумуляторов по напряжению разомкнутой цепи. Преимуществом данного метода является его простота: измерить напряжение разомкнутой цепи (НРЦ) может и не специалист по эксплуатации ХИТ. Недостаток: точное определение состояния ХИТ с неизвестной предысторией эксплуатации по величине НРЦ проблематично.
Метод определения состояния ХИТ
по напряжению под нагрузкой. Преимуществами метода являются простота реализации и малое время для оценки состояния ХИТ. Недостатками метода являются: пригоден в качестве оценочного только для полностью заряженных (разряженных) ХИТ; при измерении существует прямая зависимость измерений рабочего напряжения от технического состояния элементов коммутации (проводов, игл, зажимов и т.д.). 
Метод определения состояния ХИТ по внутреннему сопротивлению. Преимущество метода состоит в том, что по информации об омическом сопротивлении можно выявить все зависимости между конструктивными и технологическими параметрами и конечными характеристиками ХИТ.
Однако этот метод имеет и существенные недостатки: он предназначен только для определенного типа электрохимических систем (индивидуальные характеристики (параметры) для каждого типа ХИТ; критичность к напряжению на проверяемом ХИТ и

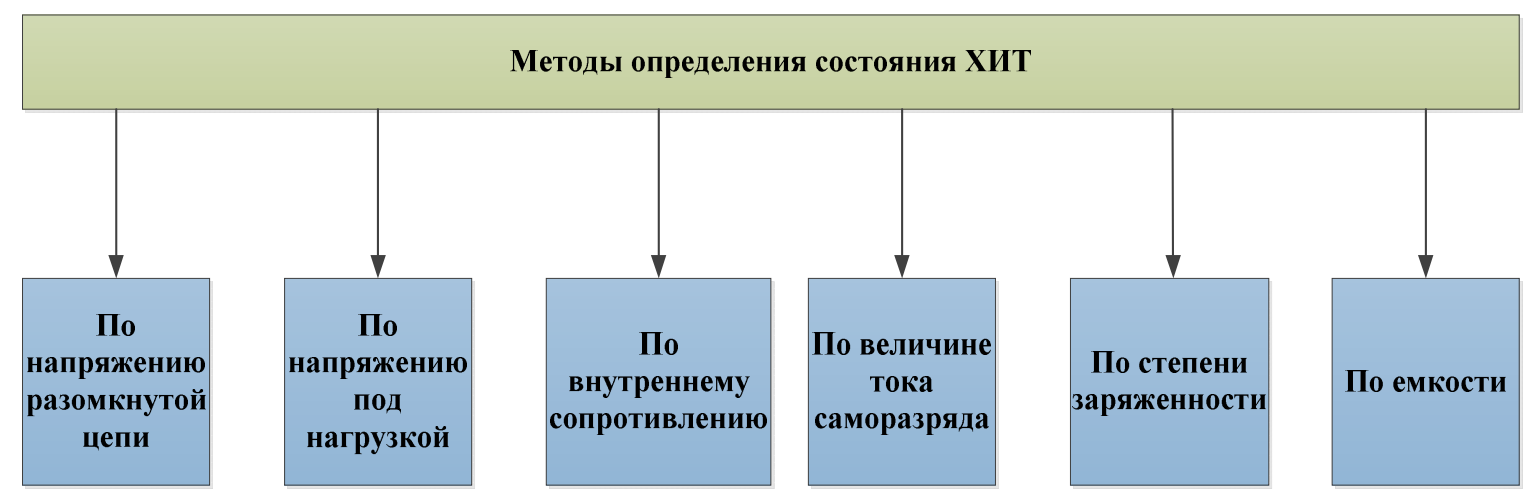

Рис. 2. Методы определения состояния ХИТ

$\begin{array}{lcr}r \text { Метод определения состояния ХИТ } \\ \text { по величине } & \text { тока } & \text { саморазряда. } \\ \text { Применение } & \text { данного }\end{array}$ целесообразно для ХИТ, подверженных большому саморазряду; по потере емкости во времени возможна оценка состояния ХИТ. Недостатком метода является невозможность быстрой оценки состояния ХИТ, т. к. исследования потери емкости ХИТ занимают весьма продолжительное время.

Метод определения состояния ХИТ по степени заряженности. В настоящее время отсутствуют методы эффективного определения степени заряженности (разряженности). При эксплуатации для определения емкости ХИТ применяют метод прямого разряда-заряда, но этот способ длительный.

Метод определения состояния ХИТ по емкости. Недостаток метода - большая длительность и значительная трудоемкость. В настоящее время быстрого и качественного способа измерения электрической емкости ХИТ не существует. Основным преимуществом этого метода является существующая зависимость напряжения и тока разряда от времени проведения разряда, высокая точность определения емкости ХИТ [5].

Экспериментальная часть. С целью обеспечения подтверждения заданных требований была создана экспериментальная база (стенд), структурная схема которого показана на рис. 3. В состав ХИТ входят несколько аккумуляторных батарей (АК). В состав стенда для циклирования ХИТ при различных температурах входят:

a) программируемый источник питания (ИП);

б) система управления (СУ) персональный компьютер;

в) термокамера (ТK);

г) регулятор температуры (РТ);

д) устройство многоканального измерения температуры (УМИТ);

е) блок преобразователей и нагрузки.

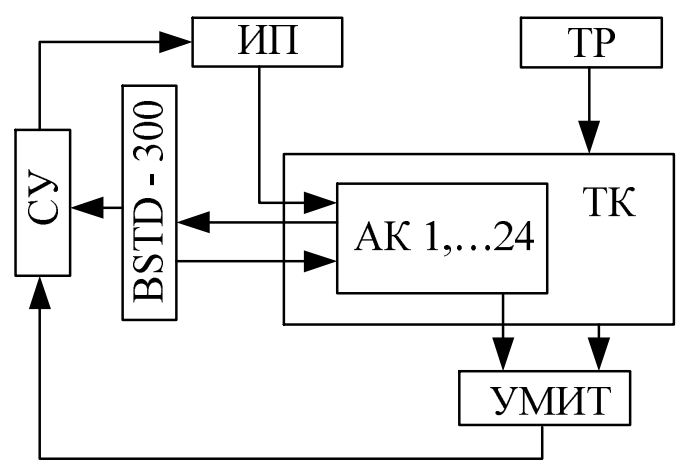

Рис. 3. Структурная схема стенда

В ТК помещались последовательно по одному ХИТ. Температура в камере устанавливалась определенной величины с 
помощью РТ и контролировалась УМИТ. В качестве разрядного устройства использовался BSTD-300, в составе которого находится интерфейсный модуль и измерительный шунт. В качестве зарядного устройства использовался трехканальный ИП. Последовательность циклов и соответствующую величину тока определяло разработанное в лаборатории программное обеспечение. В целом эксперимент управлялся с помощью ПК. На него же регистрировались результаты. Данные по измерению температуры фиксировались отдельно с помощью программного обеспечения УМИТ.

Результаты эксперимента представлены на рис. 4 и рис. 5. Были получены следующие результаты (пример):

- на рис. 4 изображены зарядноразрядные характеристики ХИТ (циклирование при температуре $25^{\circ} \mathrm{C}$ );

- на рис. 5 изображены зарядная и разрядная емкости ХИТ (циклирование при температуре $25^{\circ} \mathrm{C}$ ).

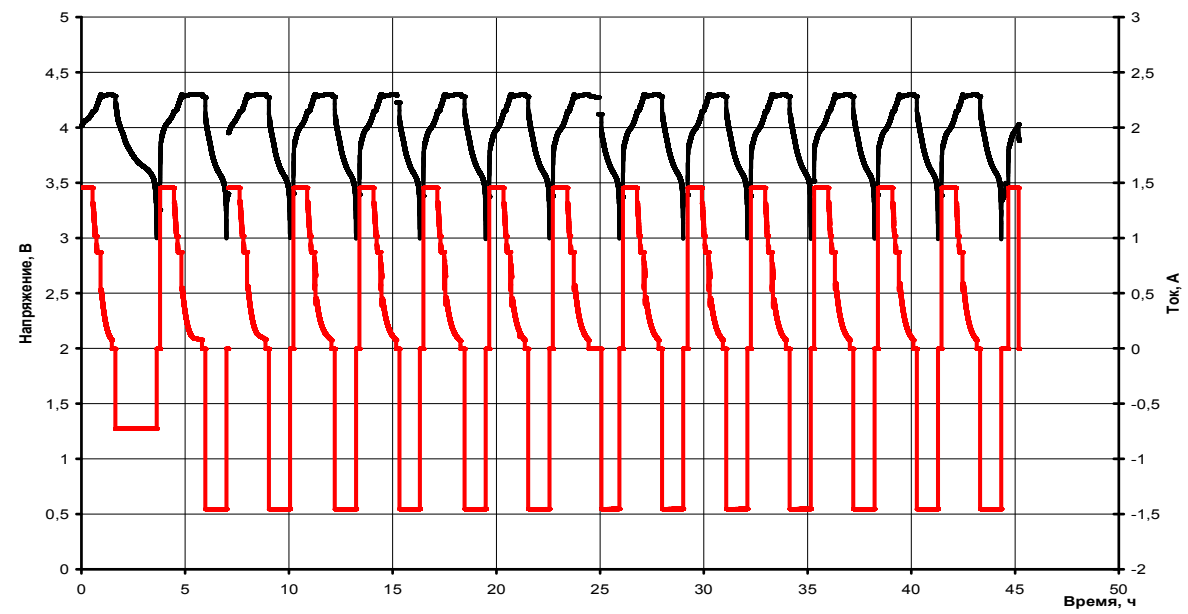

Рис. 4. Зарядно-разрядные характеристики ХИТ

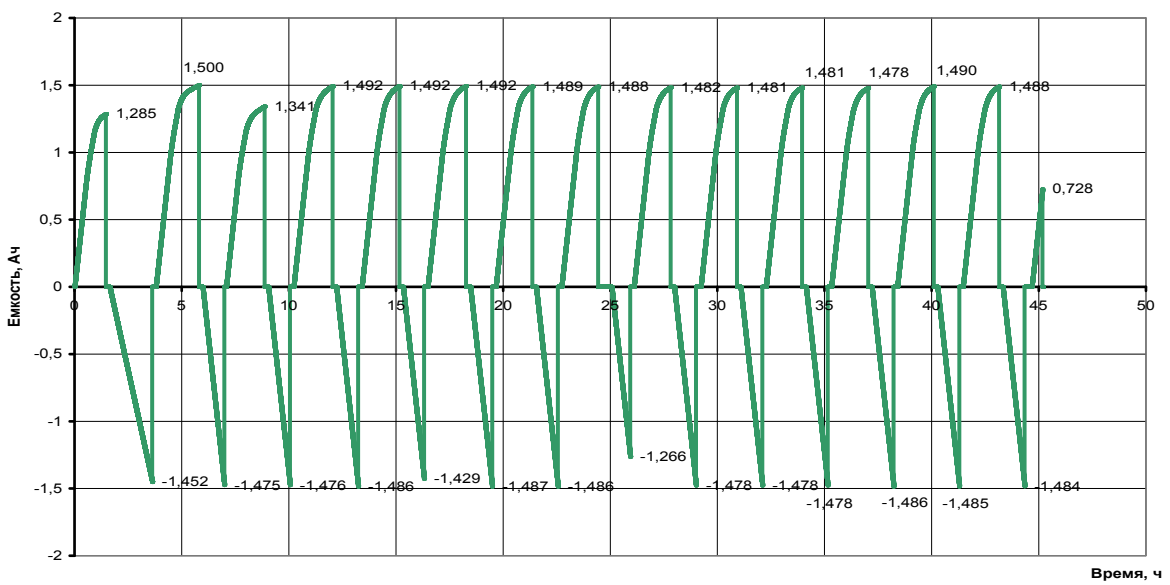

Рис. 5. Зарядно-разрядные емкости ХИТ

Математическая модель. Результаты циклирования подтвердили увеличение емкости и напряжения ХИТ при повышенной температуре по сравнению с нормальной температурой. В этой связи необходимо разработать математическую модель (ММ) для приведения результатов измерений, полученных в процессе ускоренных ресурсных испытаний (УКИ), к нормальным условиям. Модель должна отражать зависимости параметров и характеристик состояния ХИТ от температуры и величины тока. Следует заметить, что зарядная характеристика для определения состояния ХИТ в данной работе не рассматривается.

Структура ММ имеет вид, представленный на рис. 6. 


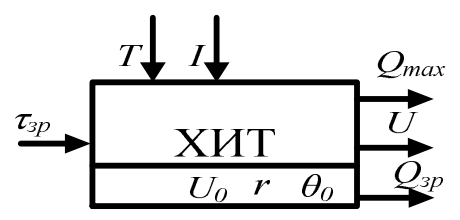

Рис. 6. Структура математической модели

Основным выходным параметром ХИТ в математической модели является напряжение разряда, входным продолжительность разряда.

На разрядное напряжение ХИТ, влияют, в основном, ток разряда и температура (факторы, связанные с нештатными режимами эксплуатации, здесь не рассматриваются).

Для построения уравнений, связывающих параметры МM, были использованы эквивалентные электрические схемы замещения, представляющие собой определенным образом соединенные активные и реактивные элементы, каждый из которых имитирует определенный физикохимический параметр исследуемого ХИТ или конструктивный элемент ХИТ [5].

Первый блок состоит из элемента, представляющего собой источник идеальной ЭДС, напряжение которого равно:

$$
U_{1}=E .
$$

Второй блок представлен резистором $R$, который описывает активационноомическую часть в работе АБ. Падение напряжения на этом элементе:

$$
U_{2}=R \cdot I \text {. }
$$

где $\quad I-$ постоянный внешний ток.

Третий блок схемы замещения АБ представляет собой конденсатор $\mathrm{C} 1 \mathrm{c}$ утечкой электроэнергии на резисторе $r$. Этот блок описывает переходные процессы, протекающие в аккумуляторе при его включении на разряд. При пропускании через схему замещения постоянного разрядного тока уравнение, описывающее процессы в блоке, имеет вид:

$$
U_{3}=-b \cdot\left(1-\exp \left(-\frac{I \cdot t}{C_{1} \cdot b}\right)\right) \text {. }
$$

Последний, четвёртый, блок схемы замещения представлен псевдоконденсатором $\mathrm{C} 2, \quad$ который соответствует основной токообразующей электрохимической реакции. При пропускании через схему постоянного разрядного тока уравнение, описывающее процессы в блоке, имеет вид:

$$
U_{4}=\frac{Q}{C_{2}} \cdot \ln \left(1-\frac{I \cdot t}{Q}\right) .
$$

Так как все блоки схемы замещения соединены последовательно, то напряжение на выходе схемы замещения будет определяться алгебраической суммой. Таким образом, искомая зависимость напряжения от времени и тока для разряда имеет следующий вид:

$$
\begin{aligned}
U=E-R \cdot I+b & \cdot\left(\exp \left(-\frac{I \cdot t}{C_{1} \cdot b}\right)-1\right)+ \\
& +\frac{Q}{C_{2}} \cdot \ln \left(1-\frac{I \cdot t}{Q}\right) .
\end{aligned}
$$

Так как аккумулятор до момента начала тестирования уже мог отдать некоторую долю ёмкости q, то с учётом этого разрядная характеристика может быть представлена в виде [5; 6]:

$$
\begin{gathered}
U=E-R \cdot I+b \cdot\left(\exp \left(-\frac{q+I \cdot t}{C_{1} \cdot b}\right)-1\right)+ \\
+\frac{Q}{C_{2}} \cdot \ln \left(1-\frac{q+I \cdot t}{Q}\right) .
\end{gathered}
$$

Выводы. Одним из способов подтверждения работоспособности ХИТ и определения времени их дальнейшей безотказной работы являются УКИ. В связи с этим изучение зависимостей влияния температуры на разрядные характеристики ХИТ является актуальной задачей. Предложенный метод УКИ позволит подтверждать или опровергать возможность дальнейшего использования ХИТ в составе СЭС мобильных и стационарных комплексов.

Четыре тренировочных цикла при УКИ показали одинаковые емкости ХИТ, что подтвердило их идентичность.

Последующие десять циклов проводились при различных температурах. Результаты циклирования показали, что 
при повышенной температуре происходит ускорение процессов, в связи с чем увеличивается разрядная емкость ХИТ.

Результаты циклирования показали увеличение емкости и напряжения ХИТ при более высокой температуре по сравнению с нормальной. Полученная зависимость позволяет в процессе проведения УКИ отслеживать фактическую емкость ХИТ и с помощью математической модели приводить разрядные характеристики ХИТ, полученные при повышенной температуре, к нормальной.

Проведенные УКИ в полной мере обеспечивают определения характеристик ХИТ с целью подтверждения возможности их использования в составе систем электроснабжения.

\section{Библиографические ссылки}

1. Хрусталев Д.А. Аккумуляторы. Москва : Изумруд, 2003. 224 с.

2. Вырыпаев В.Н. и др. Химические источники тока : уч. пособ. для хим.технол. спец. вузов. Москва : Высш. шк., 1990. $240 \mathrm{c}$.
3. Накопители энергии : учеб. пособие для вузов / Д.А. Бут, Б.Л. Алиевский, С.P. Мизюрин, П.В. Васюкевич. Москва Энергоатомиздат, 1991. 400 с.

4. Земляной К.Н., Рева В.С., Фролов В.П. Анализ режимов работы и выбор химического источника тока из состава систем электроснабжения самоходной пусковой установки. Космическая техника. Ракетное вооружение. 2016. № 2. С. 52-56.

5. Давидов. А.О. Основные эксплуатационные параметры и классификация режимов работы электрохимических аккумуляторов. Авиационно-космическая техника и технология. 2011. № 7 (84). С. 120-125.

6. Клочкова. Л.Л., Щербаков А.Н. Оценка характеристики энергоустановок с ХИТ на ранней стадии проектирования: учеб. пособие. Москва : Изд-во МАИ, 1993. $76 \mathrm{c}$.

Надійшла до редколегії 01.07.2018 p.

\section{ОПРЕДЕЛЕНИЕ ДЕФОРМИРОВАНИЯ ИСХОДНОГО ПРЯМОУГОЛЬНОГО СЕЧЕНИЯ ПРОФИЛЬНЫХ ЗАГОТОВОК ПРИ ИЗГОТОВЛЕНИИ ГИБКОЙ ЭЛЕМЕНТОВ КОНСТРУКЦИЙ ИЗДЕЛИЙ АЭРОКОСМИЧЕСКОЙ ТЕХНИКИ ТИПА ШПАНГОУТ}

Е.Г. Седачова ${ }^{1}$, А.В. Кулик ${ }^{2}$ Н.Н. Убизький ${ }^{2}$

${ }^{1}$ Днепровский колледж ракетно-космического машиностроения

2 Днепровский национальный университет имени Олеся Гончара

Розроблено математичну модель для визначення деформування прямокутного перетину заготовок при згинанні. перетину.

Ключові слова: згинання, заготовки, прямокутний перетин, деформування прямокутного

The worked out mathematical model is for determination of deformation of the rectangular crossing of purveyances at bending.

Keywords: bending, purveyances, rectangular crossing, deformation of the rectangular crossing.

Разработана математическая модель для определения деформирования исходных прямоугольных сечений заготовок при изгибе.

Ключевые слова: гибка, заготовки, прямоугольное сечение, деформирование прямоугольного сечения.

Постановка задачи. При изготовлении элементов конструкций ротационной гибкой из заготовок, имеющих исходное прямоугольное сечение. наряд $\mathrm{c}$ основным (C) Седачова Е.Г., Кулик А.В., Убизький Н.Н., 2018 формоизменением заготовок - приданием требуемой кривизны, имеет место искажение формы поперечного сечения. Боковые стороны сечения поворачиваются, оставаясь прямыми, а две другие стороны 